\title{
Opinion of the junior doctors on the existing morale, support and autonomy at their workplace and the factors positively influencing them
} Rahman KR ${ }^{a}$, Tabassum $\mathbf{N}^{b}$, Mollah AH $^{c}$

\begin{abstract}
Background: Junior doctors form the majority of the workforce in patient care. Their job is perilous, highly critical, tedious and exhausting and it is imperative that they stay motivated while at work. Improving the morale of physicians has the potential to increase efficiency, ensure patient safety and improve patient outcomes. We aimed to identify the existing status and explore the factors affecting junior doctors' morale, their sense of feeling supported and their levels of autonomy in 2 large teaching hospitals in Bangladesh.

Methods: This cross-sectional observational study was done across 2 large tertiary hospitals- Bangladesh Institute of Research and Rehabilitation in Diabetes, Endocrine and Metabolic Disorders(BIRDEM) General Hospital and Dhaka Shishu Hospital, over 4 months period from September-December 2020. The study was carried out on 120 junior doctors by an online questionnaire, distributed through emails and Facebook messenger, asking junior doctors to rate their morale, sense of feeling supported and autonomy and rank the top factors that positively affected them.

Results: Data were finally collected from 117 junior doctors after 3 incomplete data were discarded. Most of the junior doctors felt 'neither good nor bad' in the domains of existing 'morale' (44.4\%), 'feeling supported' (46.5\%) and 'autonomy'(48.7\%). Additionally, 'good'morale was seen in 39.3\%, while around 34\% rated their support system as 'good' and around $24 \%$ reported a 'good' autonomy. The most important factor positively affecting morale was recognition and reward for good performance (70.1\%), factor influencing support was an easy access to senior clinicians (70.4\%) and that defining autonomy was constant senior supervision of the everyday work (61.1\%).

Conclusion: The study aims to identify the existing level of morale, support and autonomy of the junior doctors at their workplace and explore the factors positively affecting them. It is concluded from this study that the junior doctors rated their existing morale, support and autonomy as 'average'. According to the opinions of the doctors, this study also concludes that, to improve their morale, there is a need to recognize and reward their good work and provide positive feedback. Doctors identified an easy access to senior clinicians with a problem was the primary factor influencing support. Finally, junior doctors wanted constant senior supervision of their everyday work in the wards to improve output.
\end{abstract}

Key words: Autonomy, junior doctors, morale, support.

(BIRDEM Med J 2022; 12(1: 30-35)

\section{Author information}

a. Khandakar Rezwanur Rahman, FCPS Part II Trainee (Surgery), Department of Emergency and Casualty, Dhaka Medical College Hospital (DMCH), Dhaka, Bangladesh.

b. Nabila Tabassum, FCPS Part II Trainee (Pediatrics), Dhaka Shishu Hospital, Dhaka, Bangladesh.

c. Md. Abid Hossain Mollah, Professor and Head, Department of Pediatrics, BIRDEM General Hospital, Dhaka, Bangladesh.

Address of correspondence: Khandakar Rezwanur Rahman, FCPS Part II Trainee (Surgery), Department of Emergency and Casualty, Dhaka Medical College Hospital (DMCH), Dhaka, Bangladesh. Email: rkh.rezwanur@gmail.com Received: May 31, 2021

Revision received: October 16, 2021

Accepted: October 31, 2021

\section{INTRODUCTION}

Junior trainee doctors are the main workforce undertaking patient care in the hospitals. Thus, they need to be empowered and supported within their training system. ${ }^{1}$ People have three core needs which ensure their wellbeing and motivation at work and reduce work related stress: autonomy, good morale and feeling supported. ${ }^{2}$ A high morale of junior doctors is important in medical care because it irrefutably influences their performance and efficiency and improves patient outcomes. It continues to be a challenge to effectively cater for these stress factors; however, failure in 
providing any of the 3 factors will negatively impact the productivity, effectiveness and retention within the medical workforce. ${ }^{3}$ Therefore, it is vital that such issues are investigated and acted upon.

Although an important issue, very few studies had been conducted in Bangladesh on this topic. The purpose of this study is to explore the factors that affect junior doctors' morale, autonomy and sense of feeling supported. If the factors are identified and appropriate measures taken, the overall performances and satisfaction of the junior doctors will improve, which in turn will lead to improved patient safety and better quality of patient care. The objectives of this study were to assess the existing standard of morale, support and autonomy of the junior doctors, to identify factors affecting junior doctors morale, to explore the factors which influence their sense of feeling supported and to identify factors which affect their autonomy.

\section{METHODS}

This cross-sectional observational study was done across 2 large tertiary hospitals- Bangladesh Institute of Research and Rehabilitation in Diabetes, Endocrine and Metabolic Disorders(BIRDEM) General Hospital and Dhaka Shishu Hospital, over 4 months period from September-December 2020. A total of 120 junior doctors of these hospitals participated in this survey with age ranging from 25-35 years and their opinions were collected via online survey. Three incomplete data were discarded and the final sample size was 117 , with a response rate of $97.5 \%$.

Discussions took place with professors, senior clinicians and junior doctors and an online questionnaire was developed with their input, designed to capture a comprehensive picture of junior doctor morale. The domains explored in our study have shown to influence the morale, sense of feeling supported and autonomy in the workplace, in a recent report. ${ }^{4}$ The questionnaire was piloted initially among 30 doctors to test and refine it and their inputs and opinions were added before final dispatch.

The questionnaire was distributed by email and Facebook messenger containing individualized links. Periodic automatic reminders were sent.

Respondents rated their overall morale, how supported and how autonomous they felt at work using an ordinal Likert scale of 1 (low) to 5 (high). In addition, respondents selected the top five factors that positively affected their morale, top five factors that made them feel supported and the most important factor that affects how much autonomy they get during their work from a list of options. After collection, the data were checked, verified, edited meticulously to reduce error and compiled for presentation.

Junior doctors: For the purpose of this study, doctors with age ranging from 25 years to 35 years, either in post graduate training (either FCPS/MD/MS/Diploma course) or medical officers in non-training posts, were defined as junior doctors.

Morale: It is defined as the extent to which an employee feels good about his /her work and work environment. ${ }^{5}$

Support: It refers to social interactions, help and resources that are received from seniors, teachers, administrative staff and co-workers when required. Support is essential to manage uncertainty, help in coping and diminish occupational stress. ${ }^{6}$

Autonomy: It is the physician's ability to utilize professional judgement to make clinical decisions that best meet the needs of patients. Autonomy helps determine settings that support each physician's ability to fulfill his or her professional duty to care for patients or control that employees have over their work patterns. ${ }^{7}$

\section{RESULTS}

In this study, all the junior doctors were specialist trainee (either FCPS or MD/MS course) or medical officers in nontraining posts. Their age ranged from $25-35$ years, with $78.6 \%$ between $20-25$ years and $21.3 \%$ between $30-35$ years.

The responses of the junior doctors regarding their morale at the workplace are given in Table I below.

Table I The self-reflection of the junior doctor's morale at their workplace

\begin{tabular}{llc}
\hline Grade & Morale & $\begin{array}{c}\text { Number of respondents } \\
\text { (Percentage) }\end{array}$ \\
\hline 1 & Very bad & $4(3.4)$ \\
2 & Bad & $14(12)$ \\
3 & Neither good nor bad & $52(44.4)$ \\
4 & Good & $46(39.3)$ \\
5 & Very good & $1(0.9)$ \\
\hline
\end{tabular}

This table shows that around $44.4 \%$ answered that their morale is 'neither bad nor good' in their workplace while $39.3 \%$ rated their morale as 'good' and $12 \%$ reported a 'bad' morale. Only $0.9 \%$ (1) respondent out of all confirmed that they have 'very good' morale, while 3.4\% (4) mentioned a 'very bad' morale .

According to their opinion the top 5 factors positively influencing their workplace morale are given in Table II. 
Table II Top 5 factors reported as having a positive impact on junior doctors' morale

No. Factor

No. of respondents

(Percentage)

$82(70.1)$

2 Regular, structured feedback from consultants

$78(66.7)$

3 Receive immediate help in any undue situation in the hospital e.g.- angry patient

69(59) attendants, dispute with someone

4 Feeling part of the team

5 To have easy access to your consultant regarding any issue

6 Somewhere to rest and store your belongings securely like doctor's room, clean bathroom/toilet, locker etc.

7 Ease of sick/annual/study leave process(s)

8 To have adequate dormitories for doctors and their families within hospital premises.

9 Having access to hot food and drinks

10 Opportunities to attend seminars, workshops or other learning events

11 Opportunities for nonclinical working e.g. Audits, research

12 Having access to a computer or workstation for educational purposes

13 Opportunities to teach peers or juniors/medical students
From this table it is evident that the junior doctors voted 'being recognized for their good practices', regular, structured feedback from consultants, receiving immediate help in any undue situation in the hospital, feeling part of the team, and easy access to the consultant regarding any issue as the top 5 factors out of 13 that positively and strongly influenced their morale.

Table III shows the junior doctors opinion regarding how they are supported in their workplaces.
It is seen that around $47 \%$ doctors said that the support they receive at their workplace is 'neither good nor bad'. Around $33.3 \%$ responded that they have 'good' support, and $11.4 \%$ responded that the support system is 'bad' in their workplace. Around $8 \%$ said that they don't feel supported at all, while only $0.9 \%$ (1) doctor said that they feel very supported.

According to their opinion the top 5 factors positively influencing their workplace support are enlisted in Table IV.

Table III The opinion of the junior doctors on 'how supported' they feel at their workplace

\begin{tabular}{llc}
\hline Grade & Character/name & Number of respondents (Percentage) \\
\hline 1 & Very bad & $9(7.9)$ \\
2 & Bad & $13(11.4)$ \\
3 & Neither good nor bad & $53(46.5)$ \\
4 & Good & $38(33.3)$ \\
5 & Very good & $1(0.9)$ \\
\hline
\end{tabular}


Table IV Factors reported as having a positive impact on how supported junior doctors feel at their workplace

No. Factor

Number of respondents

(Percentage)

1 Ease at which a senior can be approached for any problem

$81(70.4)$

2 Getting proper pay with respect to the workload.

$75(65.2)$

3 Having a respectful work environment

4 Opportunities for flexible and tolerable work pressure

$67(58.3)$

5 If the hospital authority provides free treatment for the family members

$56(48.7)$

6 Getting transport facilities for attending duties

7 Getting support from the hospital administration

$40(34.8)$

8 To have adequate dormitories for doctors and their families within hospital premises.

9 Having regular feedback on your training and work

10 Ease of opportunity to take leave for personal life and events

11 Good interdepartmental relation for multidisciplinary approach to patient management

$35(30.4)$

12 Having input into the Rota

13 Have access to safe drinking water and food

14. Having regular picnics and outings to reduce monotony

$19(16.5)$

Regarding the factors positively impacting their support at the workplaces, Junior doctors opined that 'easy access to a senior for any problem, good pay with respect to the workload, having a respectful work environment, opportunities for flexible and tolerable work pressure and free treatment options for family members are most crucial.

The opinions of the respondents regarding their autonomy at their workplace are given Table $\mathrm{V}$.

The majority of doctors, around $48.7 \%$ rated their autonomy in workplace as 'neither good nor bad'. Around $1.7 \%$ reported "very good" autonomy, $23.5 \%$ declared to have a 'good' autonomy while $20.9 \%$ said their autonomy was 'bad' with $5.2 \%$ rating it as 'very bad'
According to their opinion the most significant factor positively influencing autonomy is given in Table $\mathrm{VI}$.

Table V Junior doctor's self-rating on 'autonomy' at their workplace

Scale Character Number of respondents (Percentage)

\begin{tabular}{llc}
\hline 1 & Very bad & $6(5.2)$ \\
2 & Bad & $24(20.9)$ \\
3 & Neither good nor bad & $56(48.7)$ \\
4 & Good & $27(23.5)$ \\
5 & Very good & $2(1.7)$ \\
\hline
\end{tabular}

Table VI Factor having the most positive impact on making doctors feel autonomous in the workplace

\begin{tabular}{llc}
\hline No & Factor & $\begin{array}{c}\text { Number of respondents } \\
\text { (Percentage) }\end{array}$ \\
\hline 1 & $\begin{array}{l}\text { To treat the patients with full independence and only involving seniors } \\
\text { when absolutely crucial. }\end{array}$ & $46(38.9)$ \\
2 & Always working under the supervision of seniors in every step of patient management & $71(61.1)$ \\
\hline
\end{tabular}


Most junior doctors (61.1\%) wanted constant (round the clock) supervision of seniors in every step of patient management, however $38.9 \%$ wanted full independence in managing a patient and only involving seniors when absolutely crucial.

\section{DISCUSSION}

The results of this survey provides a peek into the mind of junior doctors who are working in tertiary hospitals in Dhaka, Bangladesh, exploring their overall morale, how supported and how autonomous they feel at their workplace, in an effort to find out the various factors that affect them. Most of the junior doctors felt 'neither good nor bad' in the existing domains of 'morale', 'feeling supported' and 'autonomy'.

Recognition and reward for outstanding performance, structured feedback from consultants, receiving immediate administrative support in any undue situation, feeling part of the team and friendly, easily approachable consultants were the top 5 factors for maintaining good morale. Recognition and appreciation of effort are widely known to boost morale. ${ }^{8}$ Herzberg postulated factors that cause job satisfaction (termed 'motivator factors') of which 'the level of recognition by both colleagues and management' was primary. ${ }^{5}$ Similar findings were reflected in a study done by Singh et al. ${ }^{9}$ This reflects the need for positive reinforcements, praises and tangible and intangible appraisals within the unit, department and hospital, that enables a junior doctor to feel that his/her hard work is being appreciated. Being valued for good performance would further influence the feeling of identification and pride the individual has with his or her organization. Additionally, regular constructive criticism helps doctors to learn from their mistakes and hence, grow as a physician and also as a human being. 10

Doctors identified 'the ease at which a senior can be approached for any problem' as the most significant factor that makes them feel supported. Singh et al made similar observations regarding this issue. ${ }^{9}$ Other identified new factors in this study were decent pay, a respectful work environment, flexibility and tolerable work pressure and free treatment for family members.

Multiple authors have identified key components ${ }^{11-14}$ that are important to feeling more supported in the workplace including a supportive culture, engaging communications, functional multidisciplinary teams, easing administrative challenges, transport and dormitory facilities etc. Many of these factors were echoed in the themes we have identified. A significant portion of doctors rated their morale, support and their level of autonomy at work as bad to very bad (around $17-30 \%$ overall). Further research needs to be done to explore those factors that negatively impact the junior doctors, as it was not in the scope of this study. Majority of the junior doctors wanted constant (round the clock) supervision of seniors in every step of patient management, which is expected as they are still at the early stages of their training while a smaller percentage wanted full independence in managing a patient and only involving seniors when absolutely crucial. Extensive literature search did not reveal similar or opposing findings in other studies. Both groups wanted involvement from senior doctors but at different levels of patient management and further studies in these areas is crucial to understand their individual choice regarding involvement of seniors in their daily work.

\section{Conclusion}

In conclusion, the present survey helps to identify and explore the current status and the factors that affect the morale of junior doctors, as well as how supported and autonomous they feel at work. The study highlights that to improve junior doctors' sense of morale, there is a need to recognize and reward junior doctor's good work and practice a culture of positive feedback. To encourage good performance, an objective appraisal system must be implemented. The other major idea that evolved through this study was that an easy access to senior clinicians with a problem reinforced support in the workplace. Finally, it was concluded that junior doctors feel the need of constant supervision of their everyday work in the wards to improve output.

\section{Recommendations}

This was a preliminary observation of the factors influencing 3 important aspects in junior doctor's worknamely morale, feeling supported and autonomy. Further studies are warranted to work deep into this issue, taking a higher number of sample population, and a wider number of variables to better appreciate the findings of this study. Further studies need to be done to explore the factors that negatively affect the morale of junior doctors, and also the structure and extent to which they want senior involvement in their day to day work. 


\section{Limitations}

a. Junior doctors of only 2 hospitals were included, so the number of respondents is small.

b. Only factors that might positively impact were given and thus factors that negatively affect doctors were not explored.

c. There might be some selection bias as data was collected online and those inactive in social/electric media were not included.

Authors' contribution: Rahman KR conceived of the idea. All the authors supervised the project, provided critical feedback and contributed to the final version of the article. All read and approved the final manuscript to be submitted.

Conflict of Interest: Nothing to declare

\section{Funding: None}

\section{REFERENCES}

1. Chaudhuri E, Mason NC, Logan S, Newbery N, Goddard AF. The medical registrar: empowering the unsung heroes of patient care. London: Royal College of Physicians. 2013.

2. Matsuba MK, Murzyn T, Hart D. Moral identity development and community. 2014;2:520-37

3. Singh R, Kirtley J, Lakhani D, Carr S. Listening to junior doctors: exploring morale in a large NHS trust. Future Healthcare Journal 2019 Mar;6(Suppl 1):179.
4. Health Education England. Junior doctor morale: Understanding best practice working environment. 2017

5. Royal College of Physician. RCP policy. Keeping medicine brilliant: Improving Working conditions in the acute setting. 2016

6. Franz S, Zeh A, Schablon A, Kuhnert S, Nienhaus A. Aggression and violence against health care workers in Germany-a cross sectional retrospective survey. BMC health services research 2010 Dec;10(1):1-8.

7. Doctors of BC. Doctors and professional autonomy. January 5, 2017.

8. Pinder CC. Work Motivation in Organizational Behavior (2nd ed.). New York, Psychology Press. 2008.

9. Singh R, Kirtley J, Minhas JS, Lakhani D, Carr S. Exploring junior doctor morale in a UK hospital. The Journal of the Royal College of Physicians of Edinburgh 2019 Dec 1; 49(4):312-6.

10. Hardavella G, Aamli-Gaagnat A, Saad N, Rousalova I, Sreter $\mathrm{KB}$. How to give and receive feedback effectively. Breathe 2017 Dec 1;13(4):327-33.

11. Royal College of Physicians. Being a junior doctor: Experiences from the front line of the NHS. 2016;1-16.

12. General Medical Council (GMC). The State of Medical Education and Practice in the UK: 2020.

13. Faculty of Medical Leadership and Management, NHS Providers, NHS improvement. Eight high impact actions to improve the working environment for junior doctors. 2017.

14. Health Education England. Enhancing junior doctors' working lives. A progress report. 2018. 